\title{
Analysis of in-hospital mortality among people with and without Diabetes in Australian Public Hospitals (2014-2017)
}

\section{Tina Gao}

Western Sydney University

Kingsley E Agho

Western Sydney University

Milan K Piya

Western Sydney University

David Simmons

Western Sydney University

Uchechukwu L Osuagwu ( $\square$ l.osuagwu@westernsydney.edu.au )

Western Sydney University

\section{Research Article}

Keywords: Mortality, Diabetes, Hospitalisations, Standard mortality ratio, Australia

Posted Date: July 22nd, 2021

DOI: https://doi.org/10.21203/rs.3.rs-521628/v1

License: (9) This work is licensed under a Creative Commons Attribution 4.0 International License. Read Full License 


\section{Abstract \\ Background}

Diabetes is a major public health problem affecting about 1.4 million Australians, especially in South Western Sydney, a hotspot of diabetes with higher than average rates for hospitalisations. The current understanding of the international burden of diabetes and related complications is poor and there is paucity of data on hospital outcomes and/or what common factors influence mortality rate in people with diabetes in Australia. This study determined in-hospital mortality rate and the factors associated among people with and without diabetes.

\section{Methods}

Retrospective data for 554,421 adult inpatients was extracted from the population-based New South Wales (NSW) Admitted Patient Data over 3 financial years (from 2014-15 to 2016-17). The in-hospital mortality per 1000 admitted persons, standardised mortality ratios (SMR) were calculated. Binary logistic regression was performed, adjusting for potential covariates and co-morbidities for people with and without diabetes over three years.

\section{Results}

Over three years $8.7 \%$ (48,038 people) of admissions involved those with diabetes. This increased from $8.4 \%$ in $2014-15$ to $8.9 \%$ in $2016-17$ ( $p=0.007$ ). Across all age groups, in-hospital mortality rate was significantly greater in people with diabetes $(20.6,95 \%$ Confidence intervals $\mathrm{Cl} 19.3-21.9$ per 1000 persons) than those without diabetes $(11.8,95 \% \mathrm{Cl} 11.5-12.1)$ and more in men than women $(23.1,95 \% \mathrm{Cl}$ $21.2-25.0$ vs $17.9,95 \% \mathrm{Cl} 16.2-19.8)$ with diabetes. The SMR for those with and without diabetes were $3.13(95 \% \mathrm{Cl} 1.78-4.48)$ and $1.79(95 \% \mathrm{Cl} 0.77-2.82)$, respectively. There were similarities in the factors associated with in hospital mortality in both groups including: aged $>54$ years, men, the widowed, those who stayed longer than 4 days or received intensive care in admission and had respiratory and cardiovascular comorbidities.

\section{Conclusions}

The study found that in-patients with diabetes continue to have higher mortality rates than those without diabetes and the Australian population. Overall, similar factors influenced mortality rate in people with and without diabetes in this region indicating that continued improved management of all inpatients is needed in order to minimise the persistent poor outcomes.

\section{Introduction}


Diabetes is a major public health problem affecting about 1.4 million Australians (4.9\%) with an additional 500,000 with undiagnosed diabetes. ${ }^{1}$ Diabetes was associated with about 1.2 million hospitalizations, representing $11 \%$ of all hospitalisations in Australia ${ }^{1}$ and contributed to about 16,700 deaths in in $2017-18$ (10.5\% of all deaths). ${ }^{1}$ Past studies showed higher mortality rate in people with diabetes than the general population of similar age, ${ }^{2}$ but there is paucity of data regarding the hospital outcomes of people living with diabetes ${ }^{3}$. People with type 1 diabetes were 2.4 times more likely to die, and type 2 diabetes were 1.4 times more likely to die than the general population. ${ }^{2}$ Analysing the trends in mortality among Australians with diabetes between 1997 and 2010, a study found a significant decrease in mortality rates among males and females with type 1 and type 2 diabetes compared with the general population. ${ }^{4}$ People with diabetes are also more likely to be admitted to hospital, stay in for longer and be readmitted as an emergency ${ }^{5}$ which increases the financial burden of diabetes that was estimated to be $\$ 14.6$ billion in direct and indirect costs to the Australian economy. ${ }^{1}$

South Western Sydney (SWS) is one of the most culturally diverse and rapidly growing populations in New South Wales (NSW) and covers both rural and suburban communities. The region was chosen for this study because it has one of the highest prevalence of diabetes (6.7\%) ${ }^{1,6}$ in Australia, poorer health outcomes among the residents, higher death rates and diabetes related hospitalisations ${ }^{7}$ than other regions. About $11 \%$ of all diabetes attributable deaths across NSW in 2011 involved residents from SWS alone $^{6}$ and such high hospitalisation rates and mortality related to diabetes are likely to contribute to an increasingly burdened health care system unless measures to reduce diabetes morbidity and mortality are put into place.

Although some factors associated with increased mortality among inpatients with diabetes are described in the literature, including complications of diabetes and specific patient characteristics ${ }^{8}$, no study has analysed the common factors associated with inpatient mortality in people with and without diabetes in this region. Diabetes related complications of the vascular system, infections, chronic kidney disease, ${ }^{9}$ cardiovascular disease and cerebrovascular disease, ${ }^{10,11}$ have been identified as leading causes of mortality in patients with diabetes but little is known about the role of such comorbidities among inpatients without diabetes. Additionally, specific patient characteristics such as increasing age, ${ }^{12}$ gender, $^{8}$ and socioeconomic disadvantage ${ }^{13}$ were shown to be significant predictors of mortality. Identifying and comparing factors associated with mortality among inpatients in Australia, is required to provide an indication of the burden of disease and identify target groups for health promotion and diabetes management. As part of a project to improve diabetes care in this region and the need for in hospital data from a defined cohort for effective monitoring, ${ }^{4}$ this study was designed to determine the mortality rates of people with and without diabetes, admitted to public hospitals in SWS local health district (LHD) over a three-year period (2014-2017). In addition, the study examined the factors associated with mortality rates among inpatients with and without diabetes.

\section{Methods}




\section{Data Sources}

The NSW Admitted Patient Data Collection (APDC) dataset ${ }^{14}$ contains demographic and mortality related data for all inpatient admissions provided by state hospitals using International Classification of Diseases 10th revision, Australian Modification (ICD-10-AM). People are coded by their place of residence rather than admission hospital. ${ }^{14}$ For this study, only public hospital APDC data of episodes of care were used..$^{15}$ The APDC dataset has been previously validated in people with and without diabetes. ${ }^{16-18}$ For instance, when APDC was used as a standard for validating self-reported diabetes status of people in the 45 and up study, the authors were able to identify $48.3 \%$ more people with diabetes whose status were not previously reported in their dataset. ${ }^{19}$

Approval for this study was obtained from the South Western Sydney Local Health District Human Ethics Research Committee as a quality improvement project (QA18/021). Permission for use of de-identified data was obtained from the data custodian. All methods were performed in accordance with the relevant guidelines and regulations.

\section{Study Population}

An extract of every hospital admission to a SWSLHD public hospital between 1 July 2014 and 30 June 2017 where the patient was 18 years or older on admission and was in hospital for least 24 hours was taken from the APDC database. Although inclusion of private hospitals would most accurately reflect shifts in volume between public and private hospitals, most acute admissions are in public hospitals, and we focussed on those. In the data registry, admissions were identified as relating to patients with diabetes if a code for diabetes (ICD -10 E10-E14) was included as a primary or secondary diagnosis. Data were available for residents from 6 out of 7 local government areas (LGAs) in SWS.

\section{Outcome Variables}

The dependent variable was death during admission in people with and without diabetes, which takes a binary form, such that death will be regarded as ( $1=$ if death occurs in the admission year) or $(0=$ if alive in the admission year).

\section{Covariates}

The independent variables included: diabetes status, year of admission (three levels: 2014-15, 2015-16 and 2016-17), demography which included age groups, sex, marital status, country of birth, place of residence (categorised as urban and peri-urban local government areas LGAs, based on the SWS Peri urban Network of Council action plan ${ }^{20}$, hospital health insurance cover (full or no hospital cover), hospital admission and medical comorbidities determined based on the International Statistical Classification of Diseases and Related Health Problems. Hospital admission included the length of stay (categorised as $</=4$ days and $>4$ days) in hospital and whether or not there was an ICU admission. Disease classification included nervous, respiratory, circulatory, digestive, musculoskeletal and connective, skin and subcutaneous, and endocrine, nutritional and metabolic systems. All hospital 
admissions $<24$ hours and those involving patients aged $<18$ years were excluded as well as admissions relating to obstetrics as they have the potential to obscure findings for women of child-bearing age. ${ }^{8}$

\section{Statistical Analysis}

The characteristics of patients with and without diabetes for each year of admission were presented using frequency tabulations. Mortality rate per 1000 admitted persons and their $95 \%$ Confidence Interval (Cl) was calculated in the diabetes and the non-diabetes group for all independent variables using a direct method. It was calculated for each subcategory of participants as number of deaths divided by the number of admissions in that subcategory (sum of deaths and alive) multiplied by $1000^{21}$. The standardized mortality ratio (SMR) was calculated using the Australian Bureau of Statistics (ABS) data 22 as the observed number of deaths divided by the expected number of deaths among adult Australians within the same period. An SMR $<1.0$ indicates there were fewer than expected deaths, SMR $=1.0$ indicates the number of observed deaths equals the number of expected deaths while SMR $>1.0$ indicates there were more than expected deaths, in the study population (excess deaths). This gave a measure of relative mortality compared with all admissions with diabetes recorded included in the analysis. This was followed by binary logistic regression which adjusted for potential covariates and comorbidities for people with and without diabetes over three years. These were used to examine the factors associated with mortality among inpatients with and without diabetes and across the study population. The results were presented as odds ratios (OR) with their $95 \% \mathrm{Cl}$. Analyses were performed using STATA version 14.1 (Stata Corporation 2015, College Station, TX, USA).

\section{Results}

\section{Characteristics of people with and without diabetes in this study}

Across the study period, there were 554,421 adult participants admitted to public hospitals in SWS between 2014-15 and 2016-17. Table 2 presents the characteristics of the study group for the three admission years. Over three years, $8.7 \%$ (48,038 people) of admissions involved those with diabetes, which increased significantly between $2014-15$ and $2016-17$ (8.4\% versus $8.9 \%, p=0.007)$. Among adults with diabetes, many were aged $65-74$ years $(26.5 \%)$, mostly males $(52.3 \%)$, who were married including de-facto relationships (59.3\%), born in Australia (37.9\%), lived in urban areas (65.3\%) and only $9.8 \%$ had hospital health insurance cover. For those without diabetes, they were mostly females (52.8\%), aged 1854 years old (42.0\%), married (56.8\%), lived in urban areas (62.8\%), born in Australia (45.7\%) and only $7.5 \%$ had hospital health insurance cover. About $2.5 \%$ and $1.0 \%$ of those with and without diabetes, respectively received intensive care in admission and majority of the participants stayed in hospital for less than 4 days (72.4\% in the diabetes group and $84.8 \%$ in the non-diabetes group) over the study period. Comorbidities of the circulatory system and digestive system diseases were more common in this population particularly in the diabetes group (Table 1).

\section{Insert Table 1 here}


A total of 6981 adults died in hospital during the study period and $14.2 \%(n=990)$ of all deaths involved people with diabetes. Table 2 presents the mortality rate per 1000 admitted persons and their $95 \% \mathrm{Cls}$ in both groups over three years. Over three years, the mortality rate across SWSLHD public hospitals was 12.6 (12.4-12.8) per 1000 admitted persons which was significantly higher in the diabetes $20.6(95 \% \mathrm{Cl}$ 19.7-21.5) than non-diabetes $11.8(95 \% \mathrm{Cl} 11.6-12.0)$ group. The mortality rate showed significant increase with age, reaching 48.3 (95\% Cl 43.9-52.6) and 48.1 (95\% Cl 46.5-49.6) per 1000 admitted persons aged 85 years and over, living with and without diabetes, respectively. Males had higher mortality rate than women but this was more predominant in people with diabetes (23.1 [95\% 21.7-24.4] versus 13.4 [95\% 16.7-19.2], per 1000 admitted persons). In both groups, there were higher mortality rates among the previously married or divorced people, and those who were born in European countries (Table 2).

\section{Insert Table 2 here}

In comparison with Europeans, Pacific-born adults had lower mortality rates in hospital, irrespective of their diabetes status. Those who stayed longer than 4 days in hospital had higher mortality rate compared with those with shorter hospital stay (1-4 days) irrespective of their diabetes status and the highest mortality rates were observed among those who received intensive care during admission $(111,95 \% \mathrm{Cl} 97.6-124.4$ and $14495 \% \mathrm{Cl} 136.7-151.2$, per 1000 admitted persons with and without diabetes, respectively).

\subsection{Standard Mortality Ratios among admitted adults with and without diabetes in SWS}

When adjusted for age and gender using the Australian population data, the SMRs ( $95 \% \mathrm{Cls}$ ) for people with diabetes in admission for the years 2014-15, 2015-16, and 2016-17 are presented in Figure 1 for people with and without diabetes. The SMRs were similar over three years but were significantly greater in those with diabetes compared with the background population. Over the study period, the SMR ( $95 \% \mathrm{Cls}$ ) in those with diabetes was $3.13(1.78-4.48)$ and $1.79(0.77-2.82)$ in those without diabetes. Over the study period, the SMR was $1.77(0.44-2.23)$ in men and $1.34(0.77-2.77)$ in women with diabetes while the corresponding SMRs in men and women without diabetes were $0.93(0.21-1.66)$ and $0.86(0.14$ -1.57), respectively, all of which were similar to the background population.

\section{Insert Figure 1 here}

\section{Factors associated with mortality among admitted adults with and without diabetes in SWS}

Table 3 presents the unadjusted and adjusted odd ratios for death during admission in both groups. The corresponding data for all patients (pooled analysis) in this study is shown in Supplementary Table 1 (S1). Among those with and without diabetes, the common factors associated with higher odds of death during admission included increasing age (55 years and over), male sex, marital status (divorced/widowed), staying longer than 4 days in admission, receiving intensive care during admission, and having a comorbidity that affected the respiratory or circulatory system in admission. 
Although the mortality rate was greater in the diabetes group compared to the non-diabetes group, this was not seen in the 85+ age group where the adjusted odds ratio was higher in the non-diabetes group (adjusted odds ratio, aOR $11.88,95 \% \mathrm{Cl} 10.63-13.28$ ) than the diabetes group (aOR 6.59, 95\% $\mathrm{Cl} 4.82-$ 9.02). In both groups, Europeans had higher odds of death in admission but this was nullified after adjusting for the potential covariates (Table 3 ). Also, staying longer than 4 days in hospital and having a respiratory comorbidity were associated with higher odds of death in the non-diabetes group than in the diabetes group.

\section{Insert Table 3 here}

\section{Discussion}

The current understanding of the international burden of diabetes-related complications is poor and there is paucity of data on a population level, for hospital mortality in Australian adults with diabetes. Using the national representative sample of more than 554000 adult admissions of people with and without diabetes from 2014-15 to 2016-17, our study provided the needed regional data on hospital outcomes of Australians living in the high-risk region of South Western Sydney. ${ }^{1,6,7}$ The study showed that over the three years, and across all ages, people with diabetes continue to have higher mortality rates compared with their counterparts without diabetes. The age standardised mortality rate among inpatients with diabetes was about three times higher than the general Australian population, and more in men than women, and this did not improve over time. Multivariable analyses revealed similarities in the drivers of mortality in both groups, with higher odds of death on admission in diabetes than the non-diabetes participants mostly in those aged 55 years and over, who were previously married, or stayed in hospital for more than 4 days and people who received intensive care during admission. Irrespective of the diabetes status, having a respiratory and circulatory system comorbidity should be considered a red flag in hospital, since it further increases their odds of death during admission.

The study showed for the first time that the standardized mortality among admitted people with diabetes in Australian public hospitals was significantly higher than the background population and remained so after three years. This finding was consistent with previous studies in non-admitted people. ${ }^{4}$ Harding et al's study 4 which used data from Australians who were registered on the National Diabetes Services Scheme between 1997 and 2010 but data was analysed based on diabetes type. They found that people with type 1 and type 2 diabetes experienced 3 and 1.2 times increased risk of all-cause mortality, respectively, over thirteen years. ${ }^{4}$ Without discriminating between diabetes type, Lind et $\mathrm{al}^{23}$ used a large diabetes population in Ontario, Canada to show that the diabetes mortality rate ratios decreased from 1.90 to 1.51 between 1996 and 2009 and decreased from 2.14 to 1.65 in a diabetes population from the U.K. Data presented from the National Survey of U.S. adult population with diabetes found that between 1997 and 2006, there was a decline of 23 and 40\% in all-cause and CVD death rates respectively, which were similar between gender. ${ }^{24}$ Allemann et al ${ }^{25}$ found that SMRs for people with type 1 and type 2 diabetes decreased significantly from 4.5 in 1974 to 3.5 in 2005 in Switzerland. The higher SMRs 
reported in their study ${ }^{25}$ compared to the present study may be related to the longer follow up periods and the fact that the previous studies were conducted when mortality from diabetes was much higher compared with the general population. In addition, the small differences with data from other studies discussed reflect differences in the populations.

This study found that men had higher mortality rate and were more likely to die in hospital compared with women, independent of the diabetes status. Mortality rates were 1.3 times as high for men as women (23.1 and 19.9 per 1,000 admitted people in SWS, respectively) and the likelihood of dying in hospital was still almost twice as high for men than women with diabetes. Consistent with our finding was the 1.7 times higher mortality rates in men than women reported in the recent Australian National survey data. ${ }^{1}$ However, Taylor et al found a higher relative risk of death in females with diabetes compared with their male counterparts in the UK (RR $2.47,95 \% \mathrm{Cl} 2.23-2.72$ versus RR $1.93,95 \% \mathrm{Cl} 1.79-2.07),{ }^{26}$ whereas among people with diabetes admitted electively to hospital, a higher additional risk of death was also found in females than males. ${ }^{8}$ In a cohort of US and Japanese participants with and without diabetes, Liu et al found a higher relative risk of mortality among US women with diabetes (HR 1.59 $p=0.01$ ) but no difference was observed among male and females in Japan. ${ }^{27}$ In an Australian study using NDSS database, men showed higher excess risk of mortality than women. ${ }^{4}$ The mixed results demonstrated by the different studies, warrants further investigation into the association between sex and diabetes related mortality.

Europeans had lower hospitalisation but higher in hospital mortality rates compared with Australians and both had higher mortality rates than Pacific people. A previous report from the Australian Institute of Health and Welfare found similar higher mortality rates among Europeans than their Australian-born counterparts. ${ }^{28}$ Although, an increased prevalence of diabetes and associated complications would be expected to lead to more frequent hospitalisations it may not always correspond with high mortality rates. ${ }^{28}$ Low hospitalisation rates may also reflect poor management of diabetes complications rather than less complications. ${ }^{29}$ The fact that ethnicity remained a significant factor even after adjusting for all the potential covariates in the multivariate analysis, suggests that ethnicity plays an important role in diabetes related complications among inpatients.

Age and marital status were also associated with in-hospital mortality in people with and without diabetes even after adjustment for all potential covariates. Older age is a known risk factor for mortality. ${ }^{12}$ The higher odds of mortality among those who were widowed was consistent with previous studies $^{30,31}$ which found about 2.2 higher risk of all-cause mortality among those who were widowed compared with married people in Iran. ${ }^{30}$ This can be attributed to the findings from a meta-analysis that marriage or support from the spouse is associated with a reduction of up to $15 \%$ in the risk of all-cause mortality. ${ }^{31}$ Thus suggesting that marriage may have a health protective effect in reducing stress and anxieties and promoting positive healthy behaviours, while not being married may adversely affect the health of individuals. ${ }^{32}$ It has also been suggested that the emotional shock of losing a spouse and a lack of social support contributed to higher mortality rate in those who were widowed. ${ }^{33}$ 
The study found that participants who received intensive care during admission had the highest odds of in hospital mortality. This was similar to the findings of a systematic review and meta-analyses, which determined that diabetes is associated with an increased morality risk in cardiac surgery patients admitted to $\mathrm{ICU}^{34}$ and this may be related to the high blood glucose levels in ICU. ${ }^{33}$ Although at the time of this study, $\mathrm{HbA} 1_{\mathrm{C}}$ has been recommended for use as a diagnostic test for diabetes in Australia, ${ }^{35}$ it was still not commonly performed during admission across SWSLHD hospitals particularly among older participants. ${ }^{36}$

Similar to previous studies, ${ }^{9-11,26,27}$ we found significant associations between comorbidities affecting the respiratory and circulatory systems and increased odds of death in people with and without diabetes. Although studies ${ }^{9-11}$ significant associations between mortality and other comorbidities including cerebrovascular, renal and vascular diseases have been reported, these were not replicated in our study. The odds of death among admitted participants who reported these comorbidities was greater in the nondiabetes than the diabetes group in the univariate analysis. However, this discrepancy was reduced after adjusting for the covariates suggesting the overall poorer health outcomes in residents of South Western Sydney compared to NSW as a whole. ${ }^{7}$

The main strength of this study is that it is population based with a large sample size. Also, the use of place of residence rather than admitting hospital to define the population removes the bias associated with secondary/tertiary care centres, as well as including people admitted to hospitals outside the district. The main limitations of the study are due to the nature of the data being used (secondary data analysis). There are several limitations, however, that should be acknowledged. The APDC is an administrative database, and there are inherent limitations with using administrative databases for research purposes. ${ }^{37}$ There was no information about type of diabetes, country of birth was used instead of ethnicity, and indigeneity are not routinely available. Also, the use of de-identified data did not allow for the identification of multiple admissions, and data were not available for one of the seven LGAs in the District. No body mass index or glucose data was used in this study, and socioeconomic status data were also not available. Furthermore, data measures of diabetes severity which affect mortality risk, including duration of diabetes and glycaemic control were not available, and thus could not be adjusted for. ${ }^{38}$

\section{Conclusions}

This population-based inpatient study provided an understanding of the burden of diabetes in the SWS region and showed that in-patients with diabetes continue to have substantially higher mortality rates than those without diabetes over three years, with up to 3 folds increase in mortality rate compared with their age matched counterparts in the general Australian population. Although there were commonalities in the factors associated with mortality in people with and without diabetes, the persistent poor outcomes highlights the need for continued improvement in the management of inpatients mostly the older men, the widowed and those with pre-existing health/comorbidities. Considering the high economic and health burden of diabetes, urgent measures such as glucose monitoring in admission and new 
interventions/treatment targeting the identified sub-groups are needed to minimise in hospital morbidity and mortality of adults in SWS. Further research into the reason for the poor outcome among hospital patients in this region are needed.

\section{Abbreviations}

SWS

South Western Sydney

SWSLHD

South Western Sydney Local Health District

LGA

Local Government Area

ABS

Australian Bereau of Statistics

NSW APDC

New South Wales Admitted Patient Data Collection

ICU

Intensive Care Unit

HbA1c

Glycated haemoglobin A1c

CVD

Cardiovascular disease

LoS

Length of stay

OR

Odds ratio

$\mathrm{aOR}$

Adjusted odds ratio

ICD-10

International classification of diseases, tenth version

SMR

Standard mortality ratio

$\mathrm{Cl}$

Confidence interval

\section{Declarations}

\section{Ethics approval and consent to participate}

Approval for this study was obtained from the South Western Sydney Local Health District Human Ethics Research Committee as a quality improvement project (QA18/021). Permission for use of de-identified 
data was obtained from the data custodian.

\section{Consent for publication}

Not applicable

\section{Availability of data and materials}

All data generated or analysed during this study are included in this published article and its supplementary information files. Data is also publicly available on request from the Centre for Health Record Linkage, which is managed by NSW Ministry of Health. Available

at: https://www.cherel.org.au/data-dictionaries\#section1

\section{Competing interests}

The authors declare that they have no competing interests

\section{Funding}

This research did not receive any specific grant from funding agencies in the public, commercial, or notfor-profit sectors.

\section{Authors' contributions}

ULO and KEA conceptualized, designed, and interpreted the data regarding the mortality rate and factors associated. KA performed the statistical analysis while ULO and TG were major contributors to interpreting the data. TG and ULO drafted the manuscript while all authors contributed in reviewing the manuscript. MP and DS supervised the study. All authors read and approved the final manuscript.

\section{Acknowledgement}

We acknowledge the Executive director, System Information and Analytics, NSW Ministry of Health for releasing the data used in this study.

\section{References}

1. AlHW. Deaths from diabetes. Canberra: Australian Institute of Health and Welfare; 202015 Jul Report No.: Cat. no: CVD 82.

2. Murray CJ, Richards MA, Newton JN, et al. UK health performance: findings of the Global Burden of Disease Study 2010. The lancet 2013;381(9871):997-1020.

3. Smerdely P. Mortality is not increased with Diabetes in hospitalised very old adults: a multi-site review. BMC Geriatrics 2020;20(1):522.

4. Harding JL, Shaw JE, Peeters A, Guiver T, Davidson S, Magliano DJ. Mortality Trends Among People With Type 1 and Type 2 Diabetes in Australia: 1997-2010. Diabetes Care 2014;37(9):2579. 
5. Follett P, Young R, Holman N. Variation in inpatient activity: P347. Diabetic Medicine 2012;29.

6. Osuagwu UL, Osuagwu J, Piya MK, Wong V, Simmons D. Prevalence of Diabetes Mellitus and Risk Factors in South Western Sydney: Where Are We Now? 2019.

7. NSW Ministry of Health SWSLHD. Population Health Needs Assessment for the Communities of South Western Sydney and the Southern Highlands. 2014.

8. Holman N, Hillson R, Young RJ. Excess mortality during hospital stays among patients with recorded diabetes compared with those without diabetes. Diabetic Medicine 2013;30(12):1393-402.

9. Vasan SK, Pittard AE, Abraham J, Samuel P, Seshadri MS, Thomas N. Cause-specific mortality in diabetes: Retrospective hospital based data from south India. Journal of Diabetes 2012;4(1):47-54.

10. de Miguel-Yanes JM, Jiménez-García R, Hernández-Barrera V, Méndez-Bailón M, de Miguel-Díez J, Lopez-de-Andrés A. Impact of type 2 diabetes mellitus on in-hospital-mortality after major cardiovascular events in Spain (2002-2014). Cardiovascular diabetology 2017;16(1):1-16.

11. Zargar A, Wani A, Masoodi S, et al. Causes of mortality in diabetes mellitus: data from a tertiary teaching hospital in India. Postgraduate medical journal 2009;85(1003):227-32.

12. Collier A, Connelly PJ, Hair M, Cameron L, Ghosh S, Waugh N. Mortality risk remains higher in individuals with type 1 diabetes: A population-based cohort study (the Ayrshire diabetes follow-up cohort [ADOC]). Diabetes, Obesity and Metabolism 2018;20(8):1965-71.

13. Scott A, Chambers D, Goyder E, O'Cathain A. Socioeconomic inequalities in mortality, morbidity and diabetes management for adults with type 1 diabetes: a systematic review. PLoS One 2017;12(5):e0177210.

14. ABS. NSW Health Department, Admitted Patient Data Collection. Canberra: Australian Bureau of Statistics; 2007.

15. NSW Ministry of Health SWSLHD. Hospitals 2019 [

16. Wubishet BL, Harris ML, Forder PM, Byles JE. Age and cohort rise in diabetes prevalence among older Australian women: Case ascertainment using survey and healthcare administrative data. PloS one 2020;15(6):e0234812.

17. Kotwal S, Webster A, Cass A, Gallagher M. Validity of Registry Data: Agreement Between Comorbidities Recorded in ANZDATA Compared to NSW Administrative Data. Nephrology 2014;19(Suppl. 4):22-.

18. Bell JC, Ford JB, Cameron CA, Roberts CL. The accuracy of population health data for monitoring trends and outcomes among women with diabetes in pregnancy. Diabetes research and clinical practice 2008;81(1):105-9.

19. Comino EJ, Tran DT, Haas M, et al. Validating self-report of diabetes use by participants in the 45 and up study: a record linkage study. BMC Health Services Research 2013;13(1):481.

20. Sydney Peri-Urban Network- Issues Paper. NSW: Sydney Peri-Urban Network of Councils; 2015 September. 
21. Ben-Tovim D, Woodman R, Harrison JE, Pointer S, Hakendorf P, Henley G. Measuring and reporting mortality in hospital patients. Canberra: Australian Institute of Health and Welfare 2009.

22. Deaths, Year of registration, Age at death, Age-specific death rates, Sex, States, Territories and Australia [Internet]. 2021.

23. Lind M, Garcia-Rodriguez L, Booth $\mathrm{G}$, et al. Mortality trends in patients with and without diabetes in Ontario, Canada and the UK from 1996 to 2009: a population-based study. Diabetologia 2013;56(12):2601-8.

24. Gregg EW, Cheng YJ, Saydah S, et al. Trends in death rates among US adults with and without diabetes between 1997 and 2006: findings from the National Health Interview Survey. Diabetes care 2012;35(6):1252-7.

25. Allemann S, Saner C, Zwahlen M, Christ E, Diem P, Stettler C. Long-term cardiovascular and noncardiovascular mortality in women and men with type 1 and type 2 diabetes mellitus: a 30-year follow-up in Switzerland. Swiss medical weekly 2009;139(39-40):576-83.

26. Taylor KS, Heneghan CJ, Farmer AJ, et al. All-cause and cardiovascular mortality in middle-aged people with type 2 diabetes compared with people without diabetes in a large UK primary care database. Diabetes care 2013;36(8):2366-71.

27. Liu L, Miura K, Kadota A, et al. The impact of sex on risk of cardiovascular disease and all-cause mortality in adults with or without diabetes mellitus: A comparison between the US and Japan. Journal of Diabetes and its Complications 2019;33(6):417-23.

28. Holdenson Z, Catanzarit L, Phillips G, Waters A. A picture of diabetes in overseas-born Australians (Bulletin No. 9. AlHW Cat. No. AUS 38). Canberra: AlHW2003.

29. Strong K, Trickett P, Bhatia K. The health of overseas-born Australians, 1994-1996. Australian Health Review 1998;21(2):124-33.

30. Ramezankhani A, Azizi F, Hadaegh F. Associations of marital status with diabetes, hypertension, cardiovascular disease and all-cause mortality: A long term follow-up study. PloS one 2019;14(4):e0215593-e.

31. Manzoli L, Villari P, Pirone GM, Boccia A. Marital status and mortality in the elderly: a systematic review and meta-analysis. Social science \& medicine 2007;64(1):77-94.

32. Wyke S, Ford G. Competing explanations for associations between marital status and health. Social science \& medicine 1992;34(5):523-32.

33. Sullivan AR, Fenelon A. Patterns of widowhood mortality. Journals of Gerontology Series B: Psychological Sciences and Social Sciences 2014;69(1):53-62.

34. Siegelaar SE, Hickmann M, Hoekstra JB, Holleman F, DeVries JH. The effect of diabetes on mortality in critically ill patients: a systematic review and meta-analysis. Critical Care 2011;15(5):1-12.

35. d'Emden M. Glycated haemoglobin for the diagnosis of diabetes. Aust Prescriber 2014;37:98-100.

36. Levi OU, Webb F, Simmons D. Diabetes Detection and Communication among Patients Admitted through the Emergency Department of a Public Hospital. Int J Environ Res Public Health 2020;17(3). 
37. Grimes DA. Epidemiologic research using administrative databases: garbage in, garbage out. Obstetrics \& Gynecology 2010;116(5):1018-9.

38. Tancredi M, Rosengren A, Svensson A-M, et al. Excess mortality among persons with type 2 diabetes. New England Journal of Medicine 2015;373(18):1720-32.

\section{Tables}

Table 1. Demographic characteristics of adults with and without diabetes admitted to South Western Sydney Local Health District hospitals by admission year and diabetes status. 


\begin{tabular}{|c|c|c|c|c|c|c|}
\hline \multirow[t]{2}{*}{ Characteristics } & \multicolumn{3}{|l|}{ Diabetes } & \multicolumn{3}{|c|}{ Non-Diabetes } \\
\hline & $\begin{array}{l}\text { July 2014- } \\
15\end{array}$ & $\begin{array}{l}\text { July 2015- } \\
16\end{array}$ & $\begin{array}{l}\text { July 2016- } \\
17\end{array}$ & July 2014-15 & July 2015-16 & July 2016-17 \\
\hline Admission year & $\begin{array}{l}14661 \\
(8.4)\end{array}$ & $\begin{array}{l}16219 \\
(8.7)\end{array}$ & $\begin{array}{l}17158 \\
(8.9)\end{array}$ & $\begin{array}{l}160265 \\
(91.6)\end{array}$ & $\begin{array}{l}169943 \\
(91.3)\end{array}$ & $\begin{array}{l}176175 \\
(91.1)\end{array}$ \\
\hline \multicolumn{7}{|l|}{$\begin{array}{l}\text { Demography } \\
\text { Age Groups }\end{array}$} \\
\hline $16-54$ & $\begin{array}{l}2854 \\
(19.5)\end{array}$ & $\begin{array}{l}3158 \\
(19.5)\end{array}$ & $\begin{array}{l}3294 \\
(19.2)\end{array}$ & $\begin{array}{l}67148 \\
(41.9)\end{array}$ & $\begin{array}{l}71341 \\
(42.0)\end{array}$ & $\begin{array}{l}75438 \\
(42.8)\end{array}$ \\
\hline $55-64$ & $\begin{array}{l}2958 \\
(20.2)\end{array}$ & $\begin{array}{l}3248 \\
(20.0)\end{array}$ & $\begin{array}{l}3475 \\
(20.3)\end{array}$ & $\begin{array}{l}25355 \\
(15.8)\end{array}$ & $\begin{array}{l}26815 \\
(15.8)\end{array}$ & $\begin{array}{l}28092 \\
(16.0)\end{array}$ \\
\hline $65-74$ & $\begin{array}{l}3894 \\
(26.6)\end{array}$ & $\begin{array}{l}4268 \\
(26.3)\end{array}$ & $\begin{array}{l}4572 \\
(26.7)\end{array}$ & $\begin{array}{l}29496 \\
(18.4)\end{array}$ & $\begin{array}{l}31508 \\
(18.5)\end{array}$ & $\begin{array}{l}31865 \\
(18.1)\end{array}$ \\
\hline $75-84$ & $\begin{array}{l}3497 \\
(23.9)\end{array}$ & $\begin{array}{l}3811 \\
(23.5)\end{array}$ & $\begin{array}{l}3975 \\
(23.2)\end{array}$ & $\begin{array}{l}25605 \\
(16.0)\end{array}$ & $\begin{array}{l}26451 \\
(15.6)\end{array}$ & $\begin{array}{l}26504 \\
(15.0)\end{array}$ \\
\hline $85+$ & $1458(9.9)$ & $\begin{array}{l}1734 \\
(10.7)\end{array}$ & $\begin{array}{l}1842 \\
(10.7)\end{array}$ & $12661(7.9)$ & $13828(8.1)$ & $14276(8.1)$ \\
\hline \multicolumn{7}{|c|}{$10020(0.1)$} \\
\hline Women & $\begin{array}{l}6916 \\
(47.2)\end{array}$ & $\begin{array}{l}7760 \\
(47.9)\end{array}$ & $\begin{array}{l}8250 \\
(48.1)\end{array}$ & $\begin{array}{l}85502 \\
(53.4)\end{array}$ & $\begin{array}{l}89714 \\
(52.8)\end{array}$ & $\begin{array}{l}91902 \\
(52.2)\end{array}$ \\
\hline Men & $\begin{array}{l}7745 \\
(52.8)\end{array}$ & $\begin{array}{l}8459 \\
(52.2)\end{array}$ & $\begin{array}{l}8908 \\
(51.9)\end{array}$ & $\begin{array}{l}74763 \\
(46.7)\end{array}$ & $\begin{array}{l}80225 \\
(47.2)\end{array}$ & $\begin{array}{l}84271 \\
(47.8)\end{array}$ \\
\hline \multicolumn{7}{|l|}{ Marital Status } \\
\hline Married/Defacto & $\begin{array}{l}8644 \\
(59.1)\end{array}$ & $\begin{array}{l}9607 \\
(59.4)\end{array}$ & $\begin{array}{l}10170 \\
(59.4)\end{array}$ & $\begin{array}{l}90373 \\
(56.6)\end{array}$ & $\begin{array}{l}96762 \\
(57.0)\end{array}$ & $\begin{array}{l}99696 \\
(56.7)\end{array}$ \\
\hline Widowed & $\begin{array}{l}4497 \\
(30.7)\end{array}$ & $\begin{array}{l}4961 \\
(30.7)\end{array}$ & $\begin{array}{l}5229 \\
(30.5)\end{array}$ & $\begin{array}{l}40611 \\
(25.4)\end{array}$ & $\begin{array}{l}41845 \\
(24.7)\end{array}$ & $\begin{array}{l}42369 \\
(24.1)\end{array}$ \\
\hline Single & $\begin{array}{l}1486 \\
(10.2)\end{array}$ & $\begin{array}{l}1616 \\
(10.0)\end{array}$ & $\begin{array}{l}1727 \\
(10.1)\end{array}$ & $\begin{array}{l}28812 \\
(18.0)\end{array}$ & $\begin{array}{l}31058 \\
(18.3)\end{array}$ & $\begin{array}{l}33810 \\
(19.2)\end{array}$ \\
\hline \multicolumn{7}{|l|}{ Place of Birth } \\
\hline Australia & $\begin{array}{l}5563 \\
(38.0)\end{array}$ & $\begin{array}{l}6073 \\
(37.5)\end{array}$ & $\begin{array}{l}6559 \\
(38.3)\end{array}$ & $\begin{array}{l}72754 \\
(45.4)\end{array}$ & $\begin{array}{l}77636 \\
(45.7)\end{array}$ & $\begin{array}{l}81034 \\
(46.1)\end{array}$ \\
\hline America & $412(2.8)$ & $469(2.9)$ & $464(2.7)$ & $3931(2.5)$ & $4450(2.6)$ & $4365(2.5)$ \\
\hline Asia & $\begin{array}{l}3751 \\
(25.7)\end{array}$ & $\begin{array}{l}4416 \\
(27.3)\end{array}$ & $\begin{array}{l}4674 \\
(27.3)\end{array}$ & $\begin{array}{l}39051 \\
(24.4)\end{array}$ & $\begin{array}{l}40798 \\
(24.0)\end{array}$ & $\begin{array}{l}42921 \\
(24.4)\end{array}$ \\
\hline Africa & $448(3.1)$ & $426(2.6)$ & $484(2.8)$ & $4610(2.9)$ & $5003(2.9)$ & $4920(2.8)$ \\
\hline Europe & $\begin{array}{l}3523 \\
(24.1)\end{array}$ & $\begin{array}{l}3673 \\
(22.7)\end{array}$ & $\begin{array}{l}3785 \\
(22.1)\end{array}$ & $\begin{array}{l}26005 \\
(16.2)\end{array}$ & $\begin{array}{l}26446 \\
(15.6)\end{array}$ & $\begin{array}{l}26633 \\
(15.1)\end{array}$ \\
\hline Pacific & $927(6.3)$ & $1128(7.0)$ & $1163(6.8)$ & 13743 (8.6) & $15389(9.1)$ & $16067(9.1)$ \\
\hline \multicolumn{7}{|l|}{ Residence } \\
\hline Peri-Urban & $\begin{array}{l}5076 \\
(34.6)\end{array}$ & $\begin{array}{l}5670 \\
(35.0)\end{array}$ & $\begin{array}{l}5913 \\
(34.5)\end{array}$ & $\begin{array}{l}59239 \\
(37.0)\end{array}$ & $\begin{array}{l}62658 \\
(36.9)\end{array}$ & $\begin{array}{l}66209 \\
(37.6)\end{array}$ \\
\hline Urban & $\begin{array}{l}9585 \\
(65.4) \\
\end{array}$ & $\begin{array}{l}10549 \\
(65.0) \\
\end{array}$ & $\begin{array}{l}11245 \\
(65.5) \\
\end{array}$ & $\begin{array}{l}101026 \\
(63.0)\end{array}$ & $\begin{array}{l}107285 \\
(63.1)\end{array}$ & $\begin{array}{l}109966 \\
(62.4) \\
\end{array}$ \\
\hline \multicolumn{7}{|c|}{ Hospital Health Insurance Cover } \\
\hline Full Hospital Cover & $1410(9.6)$ & $\begin{array}{l}1643 \\
(10.1)\end{array}$ & $1691(9.9)$ & $11262(7.0)$ & $12924(7.6)$ & $13061(7.4)$ \\
\hline No Hospital Cover & $\begin{array}{l}13251 \\
(90.4) \\
\end{array}$ & $\begin{array}{l}14576 \\
(89.9) \\
\end{array}$ & $\begin{array}{l}15467 \\
(90.1) \\
\end{array}$ & $\begin{array}{l}149001 \\
(93.0)\end{array}$ & $\begin{array}{l}157019 \\
(92.4)\end{array}$ & $\begin{array}{l}163114 \\
(92.6)\end{array}$ \\
\hline \multicolumn{7}{|c|}{ Episode Length of Stay (LoS) } \\
\hline$\leq 4$ days & $\begin{array}{l}10340 \\
(70.5)\end{array}$ & $\begin{array}{l}11739 \\
(72.4)\end{array}$ & $\begin{array}{l}12728 \\
(74.2)\end{array}$ & $\begin{array}{l}134631 \\
(84.0)\end{array}$ & $\begin{array}{l}143902 \\
(84.7)\end{array}$ & $\begin{array}{l}150787 \\
(85.6)\end{array}$ \\
\hline$>4$ days & $\begin{array}{l}4321 \\
(29.5)\end{array}$ & $\begin{array}{l}4480 \\
(27.6)\end{array}$ & $\begin{array}{l}4430 \\
(25.8)\end{array}$ & $\begin{array}{l}25634 \\
(16.0)\end{array}$ & $\begin{array}{l}26041 \\
(15.3)\end{array}$ & $\begin{array}{l}25388 \\
(14.4)\end{array}$ \\
\hline $\begin{array}{l}\text { LoS in days; Median } \\
\text { (IQR) }\end{array}$ & $2(1-5)$ & $1(1-5)$ & $1(1-5)$ & $1(1-3)$ & $1(1-3)$ & $1(1-2)$ \\
\hline $\begin{array}{l}\text { ICU Admission } \\
\text { No }\end{array}$ & 14300 & 15824 & 16692 & 158591 & 168235 & 174178 \\
\hline & & & $15 / 20$ & & & \\
\hline
\end{tabular}




\begin{tabular}{|c|c|c|c|c|c|c|}
\hline & $(97.5)$ & $(97.6)$ & $(97.3)$ & $(99.0)$ & $(99.0)$ & (98.9) \\
\hline Yes & $360(2.5)$ & $393(2.4)$ & $463(2.7)$ & $1665(1.0)$ & $1697(1.0)$ & $1979(1.1)$ \\
\hline $\begin{array}{l}\text { LoS in hours; Median } \\
\text { (IQR) }\end{array}$ & $\begin{array}{l}46(21- \\
90.5)\end{array}$ & $42(19-78)$ & $40(17-77)$ & $42(16-94)$ & $39(15-88)$ & $39(16-80)$ \\
\hline \multicolumn{7}{|c|}{$\begin{array}{l}\text { Medical Comorbidities (ICD Classification) } \\
\text { Nervous System }\end{array}$} \\
\hline Yes & $359(2.4)$ & $421(2.6)$ & $425(2.5)$ & 2985 (1.9) & $3436(2.0)$ & $3675(2.1)$ \\
\hline No & $\begin{array}{l}14302 \\
(97.6)\end{array}$ & $\begin{array}{l}15798 \\
(97.4)\end{array}$ & $\begin{array}{l}16733 \\
(97.5)\end{array}$ & $\begin{array}{l}157280 \\
(98.1)\end{array}$ & $\begin{array}{l}166507 \\
(98.0)\end{array}$ & $\begin{array}{l}172500 \\
(97.9)\end{array}$ \\
\hline \multicolumn{7}{|l|}{ Respiratory System } \\
\hline Yes & $1117(7.6)$ & $1177(7.3)$ & $1318(7.7)$ & $6881(4.3)$ & $7394(4.4)$ & $7888(4.5)$ \\
\hline No & $\begin{array}{l}13544 \\
(92.4)\end{array}$ & $\begin{array}{l}15042 \\
(92.7)\end{array}$ & $\begin{array}{l}15840 \\
(92.3)\end{array}$ & $\begin{array}{l}153384 \\
(95.7)\end{array}$ & $\begin{array}{l}162549 \\
(95.7)\end{array}$ & $\begin{array}{l}168287 \\
(95.5)\end{array}$ \\
\hline \multicolumn{7}{|l|}{ Circulatory System } \\
\hline Yes & $\begin{array}{l}1889 \\
(12.9)\end{array}$ & $\begin{array}{l}2050 \\
(12.6)\end{array}$ & $\begin{array}{l}2115 \\
(12.3)\end{array}$ & $8709(5.4)$ & $9223(5.4)$ & $9703(5.5)$ \\
\hline No & $\begin{array}{l}12772 \\
(87.1)\end{array}$ & $\begin{array}{l}14169 \\
(87.4)\end{array}$ & $\begin{array}{l}15043 \\
(87.7)\end{array}$ & $\begin{array}{l}151556 \\
(94.6)\end{array}$ & $\begin{array}{l}160720 \\
(94.6)\end{array}$ & $\begin{array}{l}166472 \\
(94.5)\end{array}$ \\
\hline \multicolumn{7}{|l|}{ Digestive System } \\
\hline Yes & $\begin{array}{l}1710 \\
(11.7)\end{array}$ & $\begin{array}{l}1887 \\
(11.6)\end{array}$ & $\begin{array}{l}1803 \\
(10.5)\end{array}$ & $12569(7.8)$ & $13319(7.8)$ & $13418(7.6)$ \\
\hline No & $\begin{array}{l}12951 \\
(88.3)\end{array}$ & $\begin{array}{l}14332 \\
(88.4)\end{array}$ & $\begin{array}{l}15355 \\
(89.5)\end{array}$ & $\begin{array}{l}147696 \\
(92.2)\end{array}$ & $\begin{array}{l}156624 \\
(92.2)\end{array}$ & $\begin{array}{l}162757 \\
(92.4)\end{array}$ \\
\hline \multicolumn{7}{|c|}{ Musculoskeletal + Connective System } \\
\hline Yes & $673(4.6)$ & $837(5.2)$ & $866(5.0)$ & $4698(2.9)$ & $5292(3.1)$ & $5584(3.2)$ \\
\hline No & $\begin{array}{l}13988 \\
(95.4)\end{array}$ & $\begin{array}{l}15382 \\
(94.8)\end{array}$ & $\begin{array}{l}16292 \\
(95.0)\end{array}$ & $\begin{array}{l}155567 \\
(97.1)\end{array}$ & $\begin{array}{l}164651 \\
(96.9)\end{array}$ & $\begin{array}{l}170591 \\
(96.8)\end{array}$ \\
\hline \multicolumn{7}{|c|}{ Skin + Subcutaneous System } \\
\hline Yes & $369(2.5)$ & $407(2.5)$ & $459(2.7)$ & $2537(1.6)$ & $3131(1.8)$ & $3158(1.8)$ \\
\hline No & $\begin{array}{l}14292 \\
(97.5)\end{array}$ & $\begin{array}{l}15812 \\
(97.5)\end{array}$ & $\begin{array}{l}16699 \\
(97.3)\end{array}$ & $\begin{array}{l}157728 \\
(98.4)\end{array}$ & $\begin{array}{l}166812 \\
(98.2)\end{array}$ & $\begin{array}{l}173017 \\
(98.2)\end{array}$ \\
\hline \multicolumn{7}{|c|}{ Endocrine, Nutritional + Metabolic System } \\
\hline Yes & $600(4.1)$ & $634(3.9)$ & $720(4.2)$ & $1896(1.2)$ & $1877(1.1)$ & $1877(1.1)$ \\
\hline No & $\begin{array}{l}14061 \\
(95.9)\end{array}$ & $\begin{array}{l}15585 \\
(96.1)\end{array}$ & $\begin{array}{l}16438 \\
(95.8) \\
\end{array}$ & $\begin{array}{l}158369 \\
(98.8)\end{array}$ & $\begin{array}{l}168066 \\
(98.9) \\
\end{array}$ & $\begin{array}{l}174298 \\
(98.9)\end{array}$ \\
\hline
\end{tabular}

Data were for those who spent at least 1 day. (n, \%) were used unless specified. ICD= International Statistical Classification of Diseases and Related Health Problems; ICU=intensive care unit; IQR=Interquartile range. tPeri urban includes Wollondilly, Camden, Wingecarribee Local Government Areas (LGA) while Urban includes Campbelltown, Fairfield, Bankstown-Lidcombe LGAs.

\section{Table 2}

Table 2. Mortality rate (per 1,000 admitted persons) in adults with and without diabetes across South Western Sydney Local Health District (SWSLHD) public hospitals (2014-15 and 2016-17). 


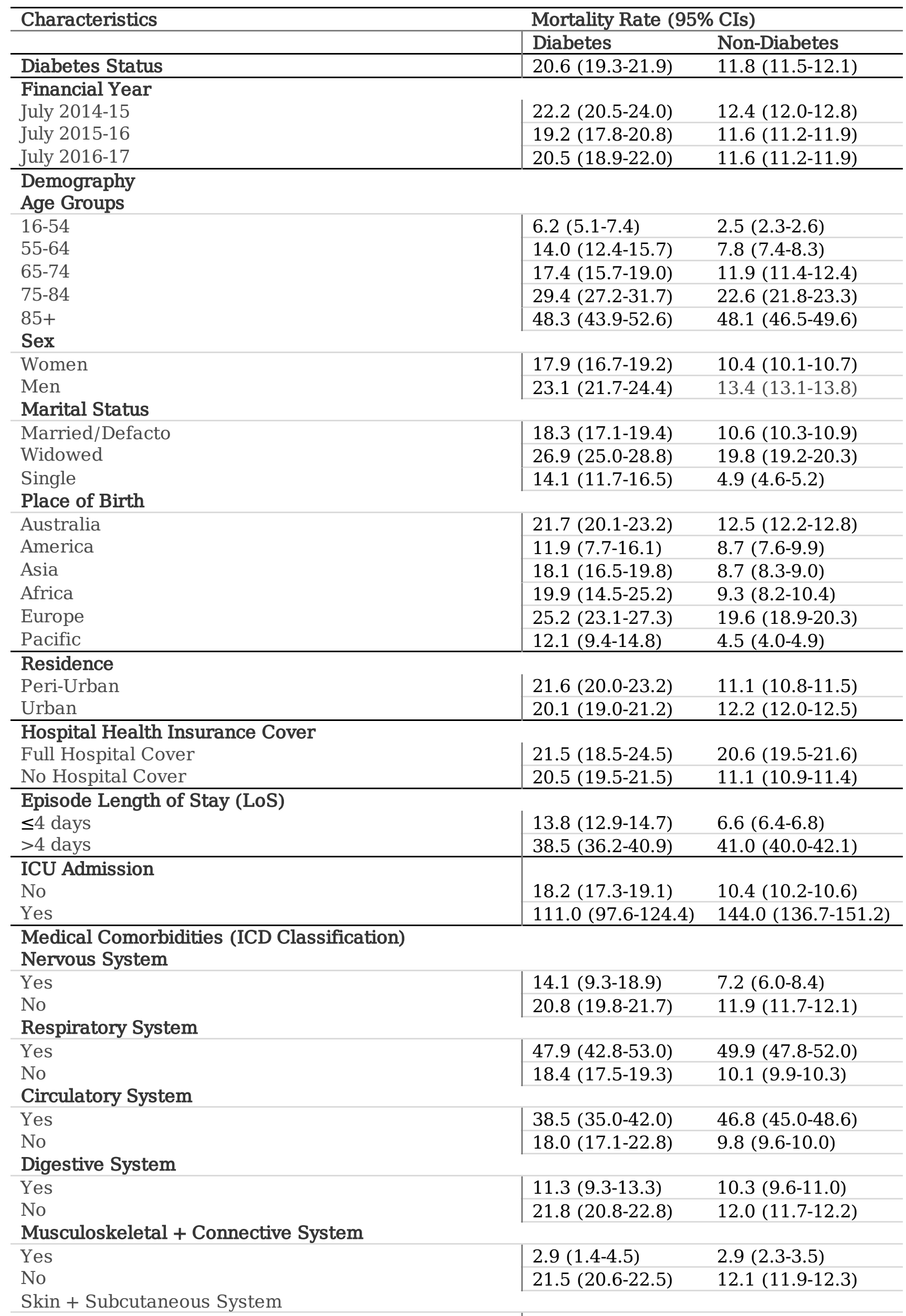




\begin{tabular}{l|ll} 
Yes & $4.0(1.5-6.6)$ & $4.8(3.7-5.8)$ \\
No & $21.0(20.1-22.0)$ & $12.0(11.7-12.2)$ \\
Endocrine, Nutritional + Metabolic System & \multicolumn{3}{l}{} \\
\hline Yes & $21.7(4.9-10.5)$ & $14.3(12.1-16.6)$ \\
No & $21.2(20.2-22.1)$ & $11.8(11.6-12.0)$ \\
\hline
\end{tabular}

ICD=International Statistical Classification of Diseases and Related Health Problems; ICU=intensive care unit; $C I=$ confidence interval

\section{Table 3}

Table 3. Factors associated with mortality among adults with and without diabetes admitted to South Western Sydney Local Health District hospitals by diabetes status. Unadjusted (OR) and adjusted odds ratios (aOR) with their 95\% confidence intervals are shown. 


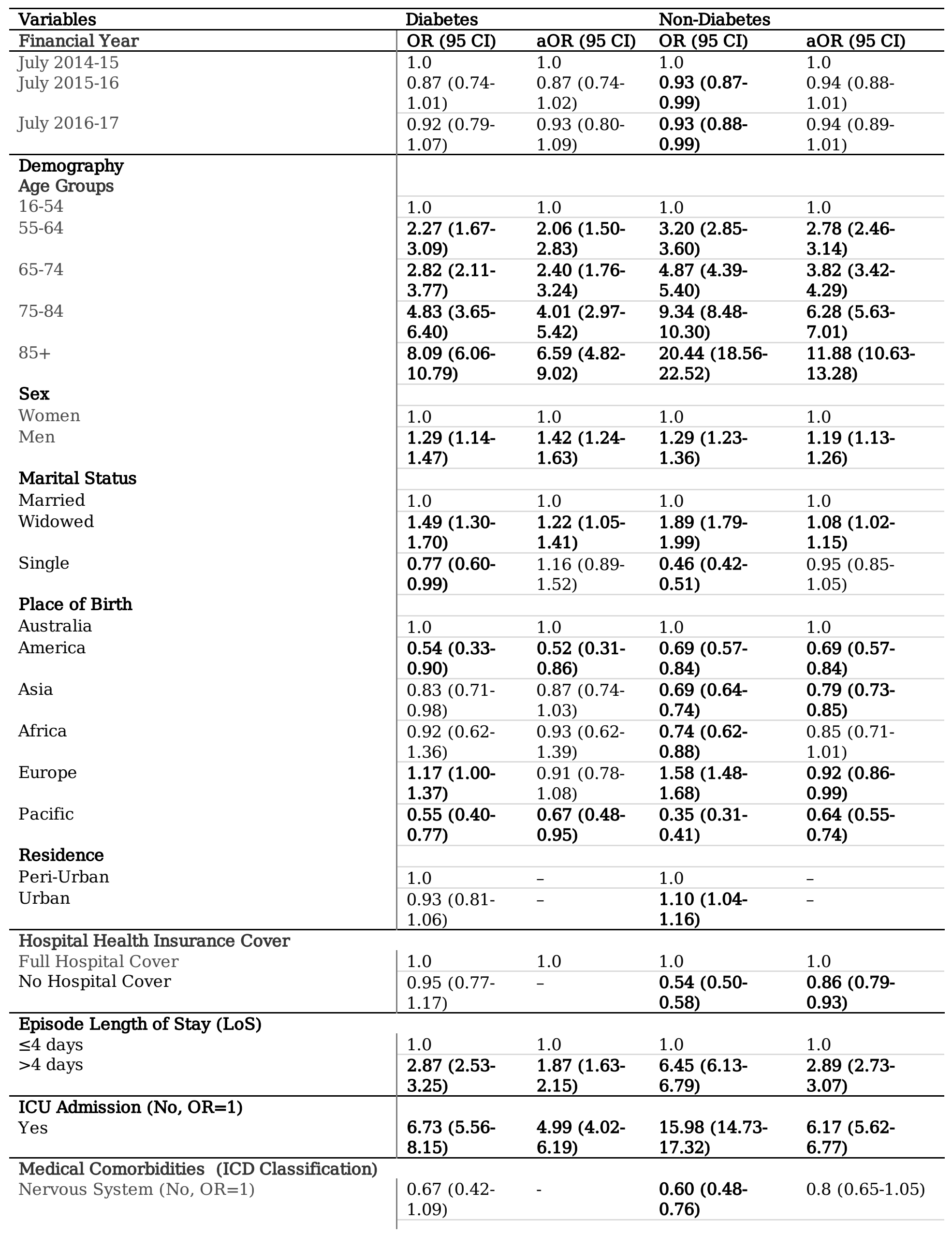




\begin{tabular}{|c|c|c|c|c|}
\hline Respiratory System (No, OR=1) & $\begin{array}{l}2.69(2.27- \\
3.18)\end{array}$ & $\begin{array}{l}2.06(1.72- \\
2.48)\end{array}$ & $\begin{array}{l}5.15(4.82- \\
5.51)\end{array}$ & $\begin{array}{l}2.95(2.73- \\
3.18)\end{array}$ \\
\hline Circulatory System (No, OR=1) & $\begin{array}{l}2.18(1.88- \\
2.53)\end{array}$ & $\begin{array}{l}1.54(1.31- \\
1.83)\end{array}$ & $\begin{array}{l}4.95(4.65- \\
5.27)\end{array}$ & $\begin{array}{l}2.47(2.29- \\
2.65)\end{array}$ \\
\hline Digestive System (No, OR=1) & $\begin{array}{l}0.51(0.40- \\
0.67)\end{array}$ & $\begin{array}{l}0.67(0.51- \\
0.88)\end{array}$ & $\begin{array}{l}0.86(0.77- \\
0.95)\end{array}$ & $\begin{array}{l}1.11(1.10- \\
1.23)\end{array}$ \\
\hline $\begin{array}{l}\text { Musculoskeletal + Connective System (No, } \\
\text { OR=1) }\end{array}$ & $\begin{array}{l}0.13(0.06- \\
0.28)\end{array}$ & $\begin{array}{l}0.17(0.08- \\
0.35)\end{array}$ & $\begin{array}{l}0.24(0.18- \\
0.32)\end{array}$ & $\begin{array}{l}0.27(0.20- \\
0.36)\end{array}$ \\
\hline Skin + Subcutaneous System (No, OR=1) & $\begin{array}{l}0.19(0.08- \\
0.46)\end{array}$ & $\begin{array}{l}0.27(0.11- \\
0.65)\end{array}$ & $\begin{array}{l}0.40(0.29- \\
0.54)\end{array}$ & $\begin{array}{l}0.51(0.37- \\
0.69)\end{array}$ \\
\hline $\begin{array}{l}\text { Endocrine, Nutritional + Metabolic System } \\
(\text { No, } \mathrm{OR}=1)\end{array}$ & $\begin{array}{l}0.36(0.21- \\
0.60)\end{array}$ & $\begin{array}{l}0.45(0.26- \\
0.75)\end{array}$ & $\begin{array}{l}1.22(0.98- \\
1.52)\end{array}$ & - \\
\hline
\end{tabular}

Empty cells in the adjusted odd ratios were variables not included in the adjusted model for lack of significance. Confidence intervals (CIs) that exclude 1.00 are significant $(p<0.05)$ and are bolded

\section{Figures}
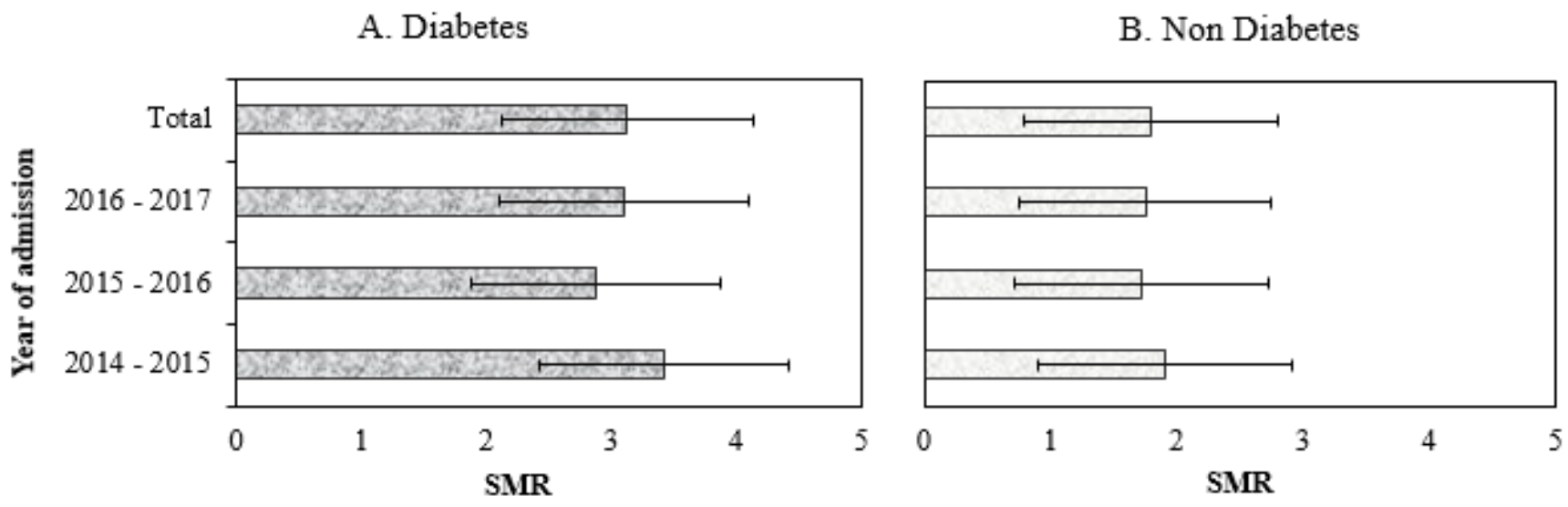

Figure 1

Standard mortality ratios (SMRs) in admitted adults with and without diabetes living in South Western Sydney Local Government Area of New South Wales, Australia. Error bars are 95\% confidence intervals of standard errors.

\section{Supplementary Files}

This is a list of supplementary files associated with this preprint. Click to download.

- SupplementaryFile.docx 